\title{
In memoriam Giuseppe Schillaci (Palermo, 27 September 1961-Perugia, 21 December 2016)
}

\author{
Giacomo Pucci ${ }^{1,2}$
}

(C) Springer International Publishing Switzerland 2017

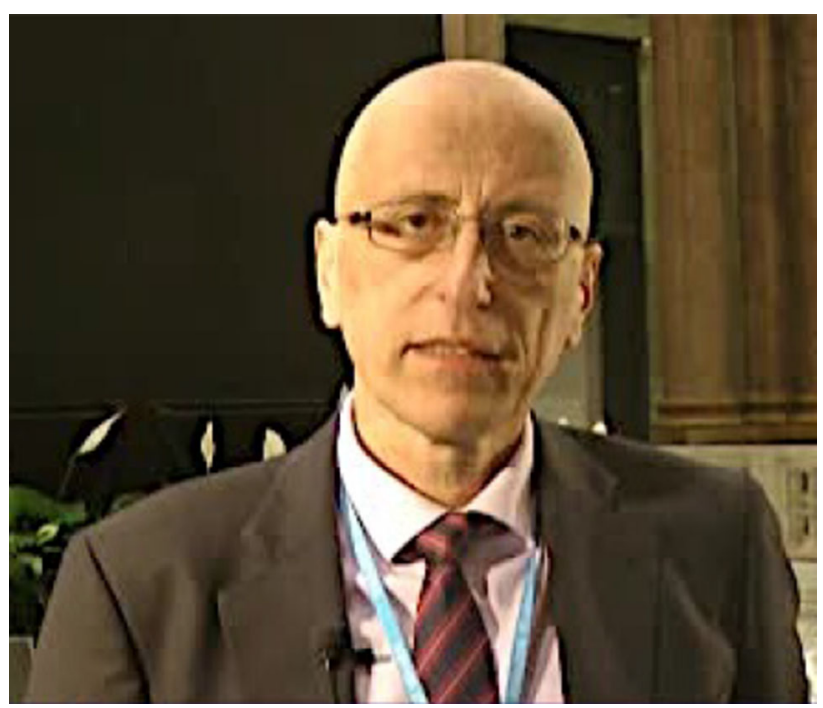

Prof. Giuseppe Schillaci was a distinguished Italian researcher, who recently and prematurely died, on last December 21, at the age of 55 years.

The photograph in this obituary represents Giuseppe Schillaci, as he appeared for a long time, during the battle against cancer he started about 5 years ago. The cancer killed him but no moments of desperation were visible in Giuseppe's face. Cancer never cracked his smile. As a matter of fact, Giuseppe knew his life was arrived at the

Giacomo Pucci

giacomo.pucci@unipg.it

1 Department of Medicine, University of Perugia, Perugia, Italy

2 Unit of Internal Medicine, Terni University Hospital, Terni, Italy final countdown since the first diagnosis of lung cancer but he always kept on working and encouraging his family, his assistants and students.

The faith in God was always with Giuseppe and, with the help of his beloved family, maintained him at workpublishing and taking care of his patients at the Perugia University Division of Internal Medicine located in Terni-until a few days before passing.

Giuseppe Schillaci started his work in hypertension research with the PIUMA project, together with his mentor Carlo Porcellati and his friend Paolo Verdecchia. The approach used by Paolo and Giuseppe was extremely innovative and led to the identification of the celebrated Perugia score to identify the electrocardiographic presence of left ventricular hypertrophy. More recently, Giuseppe has conducted a number of pivotal studies on arterial stiffness.

All papers by Giuseppe Schillaci have been widely cited and conducted him to become - as Associate Professor- the Director of the Department of Internal Medicine and the Division of Internal Medicine at the University of Perugia in Terni. Without any doubt, he merited the title of Full Professor of Internal Medicine he achieved a few time ago.

The Italian Society of Hypertension have lost his Secretary, a true friend and a distinguished researcher. We will never forget his smile. 